\title{
A challenging chat
}

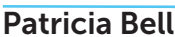

\section{At some stage or other, most haemophilia nurses will be faced with the pregnancy of an obligate carrier. As Trish Bell recounts, this can make for a difficult conversation and sleepless nights}

This poem starts in mid November A baby due in late December. I had planned for a conversation That filled me with some trepidation. The topic of which could have been a barrier

An expectant mother who's an obligate carrier.

There are things the parents needed to know

As their baby boy, up he will grow.
Patricia Bell

Clinical Nurse Specialist, Southampton Haemophilia Centre

University Hospital Southampton NHS Foundation Trust

Tremona Road, Southampton SO16 6YD Email: Patricia.Bellauhs.nhs.uk
I listened to both while each had their say (we're dealing with severe haemophilia A). This rare condition affecting The Few And chances of inheritance 1 in 2.

I gently told Daddy just what it would mean

When I explained all about this troublesome gene!

But a positive picture I ensured I did paint Especially when Dad looked like he would faint.

I avoided the tricky bits like arthropathy Affecting the joints like the ankle, the knee. And even when there was a lengthy pause I definitely avoided inhibitors.

I had all the leaflets and lots of info

To help with my teaching before they got up to go.

There's one thing I mentioned - a priority I told them about The Haemophilia Society.

But I needn't have worried our chat it went well

And Mum through December continued to swell.

We'd taken precautions to prepare for the birth

A time of excitement, anticipation and mirth.

A plan of care was unfurled

For the arrival of Junior into the world.

A cord blood sample, to the lab it did go And we'd know if he's affected, yes or no.

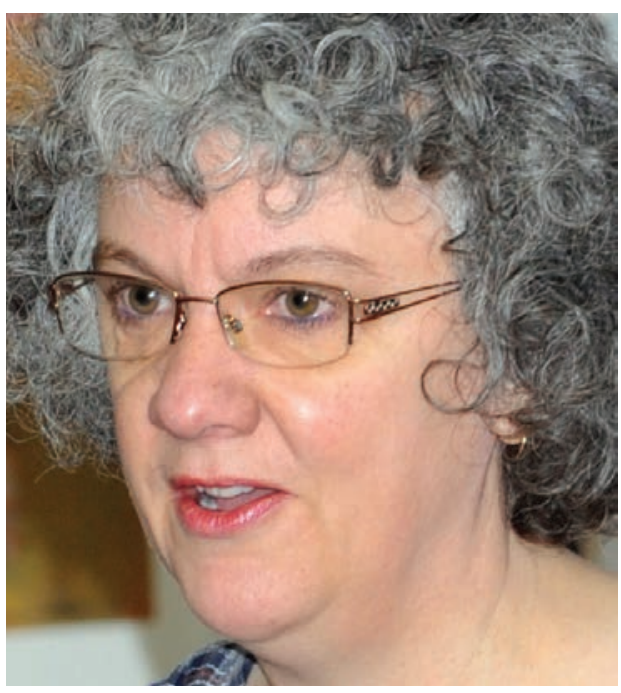

Fast forward to Christmas Eve - all was quite quiet

Suddenly the phone rang and caused a riot.

l'd had lots of tea - almost two litres And mum was in labour - about three centimetres!

I hoped when I woke upon Christmas morn

Junior would be here - having been safely born.

Reader bear with me I don't want to offend

I expect you'll be wondering - How did this all end?

So this answer - to tell you I have elected Thank goodness - this baby, he wasn't affected.

But it could have been a whole different ride

My feelings in that case are best kept inside.

\section{The Journal of Haemophilia Practice}

\author{
An open-access journal for sharing experience \\ in the care of people with bleeding disorders
}

www.haemjournal.com 